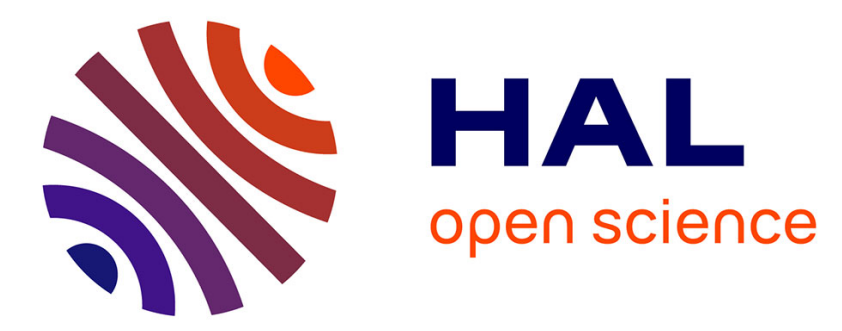

\title{
Have you anything unexpected to say? The human propensity to communicate surprise and its role in the emergence of language
}

Jean-Louis Dessalles

\section{- To cite this version:}

Jean-Louis Dessalles. Have you anything unexpected to say? The human propensity to communicate surprise and its role in the emergence of language. The evolution of language - Proceedings of the 8th International Conference (Evolang8 - Utrecht), 2010, Singapore, Netherlands. pp.99-106. hal00614791

\section{HAL Id: hal-00614791 \\ https://hal.science/hal-00614791}

Submitted on 22 Aug 2011

HAL is a multi-disciplinary open access archive for the deposit and dissemination of scientific research documents, whether they are published or not. The documents may come from teaching and research institutions in France or abroad, or from public or private research centers.
L'archive ouverte pluridisciplinaire HAL, est destinée au dépôt et à la diffusion de documents scientifiques de niveau recherche, publiés ou non, émanant des établissements d'enseignement et de recherche français ou étrangers, des laboratoires publics ou privés. 
In A. D. M. Smith, M. Schouwstra, B. de Boer \& K. Smith (Eds.), The evolution of language - Proceedings of the 8th International Conference (Evolang8 - Utrecht), 99-106. Singapore: World Scientific.

http://www.dessalles.fr/papiers/pap.evol/Dessalles_10012804.pdf

\title{
HAVE YOU ANYTHING UNEXPECTED TO SAY? \\ THE HUMAN PROPENSITY TO COMMUNICATE SURPRISE AND ITS ROLE IN THE EMERGENCE OF LANGUAGE
}

\author{
JEAN-LOUIS DESSALLES \\ Telecom PARISTECH, Paris, France \\ $\&$ \\ ILCAA, Tokyo University of Foreign Studies, Tokyo, Japan
}

\begin{abstract}
Individuals devote one third of their language time to mentioning unexpected events. We try to make sense of this universal behaviour within the Costly Signalling framework. By systematically using language to point to the unexpected, individuals send a signal that advertises their ability to anticipate danger. This shift in display behaviour, as compared with typical displays in primate species, may result from the use by hominins of artefacts to kill.
\end{abstract}

\section{Theoretical Context}

Human language has several remarkable features. It is a massive phenomenon $(M)$ : human individuals are involved more than six hours a day in spontaneous language activities (Mehl \& Pennebaker, 2003) and speak some 15000 words on average during that time (Mehl et al., 2007). Information is available in abundance, due to the existence of talkative individuals $(T)$. Many conversations deal with futile matters that are unlikely to affect the participants' survival $(F)$. Speakers do not (or loosely) discriminate who will hear what they say $(D)$, and most interactions in a group are not one-to-one (Dunbar et al., 1995). Many conversational topics are narratives, i.e. they report on some current or past unexpected event $(U)$ (Tannen 1984; Eggins \& Slade 1997; Norrick, 2000); This behaviour: drawing attention to unexpected situations, is a human distinctive feature (Tomasello, 2006) that shows up early in childhood (Carpenter et al. 1998). Human beings learn and understand huge lexicons made of tens of thousands of words and set phrases $(L)$. Most individuals willingly engage in conversational behaviour $(W)$ with no noticeable difference between sexes $(S)$ (Mehl et al., 2007). And sharing conversational time strongly correlates with establishing and maintaining social bonds (B) (Dunbar, 1996). 
Usual accounts of altruistic behaviour are at odds with these facts. Kin selection (Fitch, 2004) has problems with $M, F, D, L, B$. Reciprocal cooperation (Nowak, 2006) conflicts with $T, F, D$ and indirect reciprocity (Nowak \& Sigmund, 2005) conflicts, in addition, with $W$. Group selection (Sober \& Wilson, 1998) conflicts with $M, T, W$, and in its warrior version (Bowles, 2006) also with $S$. Though each of these theoretical difficulties should be discussed in more detail, we must observe that these traditional models of altruism cannot be straightforwardly applied to the case of human language. Moreover, none of them positively predicts any of the first seven facts in the above list.

Other accounts of costly behaviour include sexual selection (Miller, 2000) and Costly Signalling Theory (CST) (Gintis et al., 2001). Sexual selection, when applied to language, is however incompatible with facts $M, S$ and $B$. The case of CST will be examined in the next section.

We will first consider how CST can be applied to language. It requires that the quality advertised by speakers be specified. We then describe a study showing how the human mind detects and interprets unexpected events. We interpret the systematic communication of unexpected situations in our species (fact $U$ above) as a way for individuals to advertise their ability to spot unexpectedness. This advertising behaviour makes sense within the CST framework if language emerged in the new context created by the use of artefacts to kill.

\section{Can Costly Signalling Theory Account for Human Language?}

CST (Zahavi \& Zahavi, 1997; Gintis et al., 2001) appears to be the most promising model to explain the above list of facts concerning spontaneous language, despite some initial beliefs about the contrary (Zahavi \& Zahavi, 1997:222). In CST, individuals send signals, even if this involves a significant cost, to advertise a definite quality $Q$. They benefit from being perceived as possessing $Q$. In the social version of CST (Dessalles, 1999; Gintis et al., 2001), individuals establish social bonds based on $Q$. Social bonds are systematically beneficial to chosen signallers. They benefit followers as well, but only if the chosen partner really had $Q$, in other words if the signal was honest in the first place. CST shows that, under certain conditions, honest signals emerge and remain stable.

It is tempting to invoke CST to account for the existence of language, as it would correctly predict facts labelled $T, D, W, B$ in our list. There are, however, several problems. One of them is that CST is apparently incompatible with $M$ : the fact that everyone speaks, and speaks a lot. Within CST, signalling is 
competitive. This generates a threshold, below which it is not worthwhile signalling. The honesty of signals relies precisely on this fact: only high-quality individuals benefit from signalling, while the others have better time saving the cost, as they have little hope of return. We addressed this issue elsewhere (Dessalles 2006), by showing that when the competition is decentralized, even low-quality individuals benefit from signalling their true quality. The fact that social bonds imply spending time together (Dunbar, 1996) is crucial in this respect: individuals must recruit their friends among individuals who have available time left. This constraint creates a situation in which friends turn out to be matched by quality. In such situation, everyone benefits from signalling.

The major remaining problem concerning CST is that it leaves the advertised quality $Q$ unspecified. The constraints are the following:

- Joining an individual with higher $Q$ should bring more benefit to followers;

- $\quad$ Cheating on $Q$ should be difficult for signallers.

Importantly, cost is not a necessary ingredient of CST! Cost might be borne by cheaters rather than signallers (Lachman et al. 2001), and in some cases cheating might simply be impossible, e.g. if recipients can check the validity of the signal. In the next sections, we explore the possibility that one prime quality advertised through language is the ability to notice unexpected states of affairs.

\section{Unexpectedness in Language}

Some $25 \%$ to $40 \%$ of language time is devoted to mentioning immediate or past events (Eggins \& Slade, 1997; Dessalles, 2008), especially through conversational narratives (Norrick, 2000). To appear interesting to listeners, these events must appear unexpected, i.e. they must contrast with the listener's expectations about the world (see below for a more technical definition). We will show how this unique property of human communication can make sense within CST.

Unexpectedness can be given a formal definition. In their attempts to define randomness, mathematicians developed a concept known as Complexity (in the Kolmogorov sense). The complexity $C$ of a situation is the minimal information needed to reconstruct it unambiguously. Though objective (i.e. observerindependent) complexity cannot be computed, observer-dependant $C$ can be easily calculated in most concrete cases, as shown in table 1 (see www.unexpectedness.eu, or (Dessalles, 2008) for more details). 
Table 1: Complexity computations

\begin{tabular}{|c|c|c|}
\hline Parameter & C & Remark \\
\hline $\begin{array}{l}\text { Distance } d \text { to the } \\
\text { event }\end{array}$ & $\log _{2}\left(\pi d^{2} / a\right)$ & $a$ is the typical surface of the event. \\
\hline $\begin{array}{l}\text { Time distance } t \text { to } \\
\text { the event }\end{array}$ & $\log _{2}(t / a)$ & $a$ is the typical duration of event. \\
\hline Social relatedness & $\log _{2} r$ & $\begin{array}{l}r \text { is the rank of the acquaintance in the observer's } \\
\text { address or cell phone shortlist. }\end{array}$ \\
\hline Celebrity & $\log _{2} r$ & $\begin{array}{l}r \text { is the rank of the person in an ordered list (see } \\
\text { note). }\end{array}$ \\
\hline Feature $f$ & $\log _{2} r$ & $\begin{array}{l}r \text { is the rank of the notion in an ordered list (see } \\
\text { note). }\end{array}$ \\
\hline
\end{tabular}

Note: ranked lists can be obtained through Web search engines, or through temporal ordering (events being ranked by elapsed time), or by experimenting with individuals' reaction times in recognition tasks. $r$ is ideally the minimal rank obtained through such means.

Unexpectedness is defined as a complexity drop:

$$
U=C_{w}-C
$$

$C_{w}$ stands for the expected complexity, i.e. the minimal information needed for the known world to produce the situation. Table 2 shows the contribution of various parameters to unexpectedness (see www.unexpectedness.eu, or (Dessalles, 2008) for more details).

The claim is not that the human brain performs these computations formally. However, individuals seem to have clear intuitions about how these various parameters affect unexpectedness. For instance, they intuitively know that a fire breaking out next block is more unexpected, and thus more interesting to tell, than the same fire occurring five kilometres away. They intuitively know that coincidences are all the more unexpected, and thus interesting, as the two coincident facts share common features (making $C\left(s_{2} \mid s_{1}\right)$ smaller). And they know that it is highly unexpected to bump into one's neighbour $P$ in a remote place $L$ (e.g. a village in India), much more unexpected indeed than a mere encounter with some forgotten former colleague in the train station nearby (what the difference $C(P)-C(L)$ captures). The study presented in the next section puts these intuitions to the test. 
Table 2: Unexpectedness computations

\begin{tabular}{lll}
\hline \multicolumn{1}{c}{ Parameter } & $\mathrm{U}$ & \multicolumn{1}{c}{ Observation } \\
\hline Distance & $2 \log _{2}(D / d)$ & $\begin{array}{l}D \text { is the typical distance to similar events (estimated } \\
\text { by the distance to the last remembered instance). } \\
T \text { is the typical distance in the past to similar events } \\
\text { (estimated by the time distance to the last } \\
\text { remembered instance). }\end{array}$ \\
$\log _{2}(T / t)$ & $\begin{array}{l}F \text { is the occurrence frequency of feature } f . \\
\log _{2}(1 / F)-C(f)\end{array}$ \\
$0.7 k^{2}-C(f)$ & $\begin{array}{l}\text { The situation lies at } k \text { standard deviations along } \\
\text { feature } f \text { from its prototype. }\end{array}$ \\
Rarity & $C\left(s_{1}\right)-C\left(s_{2} \mid s_{1}\right)$ & $\begin{array}{l}\text { Conditional complexity } C\left(s_{2} \mid s_{1}\right) \text { measures the } \\
\text { minimal information needed to reconstruct } s_{2} \text { from } \\
s_{1} .\end{array}$ \\
The observer bumps into $P$ at location $L$.
\end{tabular}

\section{Unexpectedness and Conversational Interest}

A corpus of 18 short narratives was presented to 101 French participants (see (Dimulescu \& Dessalles, 2009) for a detailed description of the experiment). For each story, participants had to choose among two options (randomly selected out of three possible values) the one that makes the story more interesting. The following stories (originally in French) illustrate, in turn, the influence of time distance, the role of atypicality, the importance of common features in coincidences, and the influence of social proximity $(*$ signals when results are statistically significant $p<.05$ ).

- For a year, I had been thinking of changing my mobile phone at SFR (mobile operator). I finally decided to do so even if I had to pay a part because I did not have enough Red Square Points. I bought the new phone at 13:00. [---] I got a message from SFR: "Change your mobile, SFR offers you 15000 Red Square Points."

Options: (a) At 13:10; (b) At 14:00; (c) Two weeks later.

Results: (a)/(b): 29/4* - (b)/(c): 28/6* - (a)/(c): $31 / 3^{*}$

$>$ Wednesday, the city of Amiens police seized [---] kg of heroin at number 13 rue Fafet.

Options: (a) $10-$ (b) 5 - (c) 2 .

Results: (a)/(b): 28/13*-(b)/(c): 20/11 - (a)/(c): 21/8*

$>$ I'd just bought a small Peugeot 106 ColorLine for 2000 euros. I had tried it the day before and it was very good. I turned the key, I started, I left the property of the former owner of the car when, coming from the left without looking, another [---] crashed into me.

Options: (a) Peugeot 106 ColorLine - (b) Peugeot 106 - (c) Peugeot.

Results: (a)/(b) 24/8* - (b)/(c) 32/4* - (a)/(c) 28/5* 
$>$ Two weeks after my car had been stolen, the police informed me that a car that might be mine was for sale on the Internet. They showed me the ad. The phone number had been identified. It was the mobile phone number of [---]

Options: (a) my office colleague - (b) a colleague of my brother's - (c) someone of my neighbourhood.

Results: (a)/(b) 25/6* - (b)/(c) 24/10* - (a)/(c) 26/7*

Participants altogether never preferred the least unexpected option (c). For 17 stories out of 18 , the most unexpectedness option (a) was significantly ranked best. This is in perfect accordance with the major role played by unexpectedness in conversational interest. We now show that this role may owe its origin to our phylogeny.

\section{Discussion}

The human universal propensity to signalling unexpected events and the corresponding demand by listeners matches the CST prerequisite that it is used to display a social quality. What kind of quality? Candidates do not abound. There is one hypothesis, however, that seems to offer a consistent account.

It is a fact that at some point in our phylogeny, individuals started to use stones, sticks or weapons to kill at no risk (what chimpanzees do not do). This new behaviour dramatically transformed hominin politics (Woodburn 1982; Boehm 2000:177; Bingham, 2001). If anyone can kill anyone at no risk, e.g. during sleep, to be on one's guard is not enough. Individuals must rely on friends' alertness. In this context, ideal friends are those who are best able to anticipate danger. Language would have emerged as a way to advertise this ability.

In most species, danger is easy to anticipate. The gazelle knows that lions are dangerous, and it knows what the safe distance is. Chimpanzee males know that wandering close to territorial limits puts their life at risk. The problem is significantly harder for hominins: danger may come from group mates who may strike anywhere anytime by surprise. How can the unexpected be anticipated?

The present account of the evolutionary emergence of language instantiates CST in the following way: individuals, through their conversational utterances, advertise their ability to surprise others. By preferring to join and remain close to the most talented individuals in this game, listeners increase their viability as they diminish the probability of being taken by surprise. In a context of easy killing, information replaces muscular strength as main asset for success. Male chimpanzees display their muscles, whereas human beings advertise their informational abilities through language. Note that, as required by CST, it is difficult to cheat on unexpectedness, as the unexpected character of reported events can be easily checked by listeners. 
This model accounts for all the facts listed at the beginning of this paper. In particular, noticing futile facts $(F)$, such as the current date $(09 / 09 / 09)$, can make a successful communicative act (in this example, the date is interesting, not because it is consequential, but merely because it is 'too' simple and thus unexpected). The model predicts that various levels of talkativeness will coexist $(T)$; it predicts no discrimination of listeners $(D)$, no sex difference $(S)$, and of course a strong correlation between conversation and social closeness $(B)$. It is, in addition, one of the few models that account for the existence of plethoric lexicons $(L)$ : the set of unexpected situations is by definition unbounded, and one must be potentially able to describe all of them, especially the rarest ones, with enough precision for their unexpected character to be correctly appraised.

In the hominin world in which riskless killing becomes possible, individuals secure their safety by choosing the right friends, those who are most able of keeping them informed of any unusual situation going on. This is the only way to prevent the danger of being taken by surprise. The initial emergence of language may be the consequence of this situation: individuals strive to display their ability to notice anything unexpected, as it is the best way, as predicted within the CST framework, to build efficient social networks.

\section{References}

Carpenter, M., Nagell, K. \& Tomasello, M. (1998). Social cognition, joint attention, and communicative competence from 9 to 15 months of age. Monographs of the Society for Research in Child Devel., 255(63), 1-143.

Bingham, P. M. (2001). Human evolution and human history: A complete theory. Evolutionary anthropology, 9 (6), 248-257.

Boehm, C. H. (2000). Hierarchy in the forest: the evolution of egalitarian behavior. Harvard, MA: Harvard University Press.

Bowles, S. (2006). Group competition, reproductive leveling, and the evolution of human altruism. Science, 314, 1569-1572.

Carpenter, M., Nagell, K. \& Tomasello, M. (1998). Social cognition, joint attention, and communicative competence from 9 to 15 months of age. Monographs of the Society for Research in Child Dev., 255 (63), 1-143.

Dessalles, J-L. (1999). Coalition factor in the evolution of non-kin altruism. Advances in Complex Systems, 2 (2), 143-172. http://www.dessalles.fr/papiers/pap.evol/Dessalles 99091402.pdf

Dessalles, J-L. (2006). Generalised signalling: a possible solution to the paradox of language. In A. Cangelosi, A. D. M. Smith \& K. Smith (Eds.), The evolution of language, 75-82. Singapore: World Scientific.

http://www.dessalles.fr/papiers/pap.evol/Dessalles_05112301.pdf

Dessalles, J-L. (2008). La pertinence et ses origines cognitives - Nouvelles théories. Paris: Hermes-Science Publications. http://pertinence.dessalles.fr 
Dimulescu, A. \& Dessalles, J-L. (2009). Understanding narrative interest: Some evidence on the role of unexpectedness. In N. A. Taatgen \& H. van Rijn (Eds.), Proceedings of the 31st Annual Conference of the Cognitive Science Society, 1734-1739. Amsterdam, NL: Cognitive Science Society. http://141.14.165.6/CogSci09/papers/367/paper367.pdf

Dunbar, R. I. M. (1996). Grooming, gossip, and the evolution of language. Cambridge: Harvard University Press.

Dunbar, R. I. M., Duncan, N. \& Nettle, D. (1995). Size and structure of freely forming conversational groups. Human nature, 6 (1), 67-78.

Eggins, S. \& Slade, D. (1997). Analysing casual conversation. London: Equinox.

Fitch, W. T. (2004). Evolving honest communication systems: Kin selection and 'mother tongues'. In D. K. Oller \& U. Griebel (Eds.), The evolution of communication systems: a comparative approach, 275-296. Cambridge, MA: MIT Press.

Gintis, H., Smith, E. A. \& Bowles, S. (2001). Costly Signaling and Cooperation. Journal of Theoretical Biology, 213, 103-119.

Lachmann, M., Számadó, S. \& Bergstrom, C. T. (2001). Cost and conflict in animal signals and human language. Proc. Natl. Acad. Sci., USA, 98 (23),

13189-13194.

Mehl, M. R. \& Pennebaker, J. W. (2003). The sounds of social life: A psychometric analysis of students' daily social environments and natural conversations. Journal of Personality and Social Psychology, 84 (4), 857870.

Mehl, M. R., Vazire, S., Ramírez-Esparza, N., Slatcher, R. B. \& Pennebaker, J. W. (2007). Are women really more talkative than men?. Science, 317, 82.

Miller, G. F. (2000). The mating mind. New York: Doubleday.

Norrick, N. R. (2000). Conversational narrative: storytelling in everyday talk. Amsterdam: John Benjamins Publishing Company.

Nowak, M. A. (2006). Five rules for the evolution of cooperation. Science, 314, 1560-1563.

Nowak, M. A. \& Sigmund, K. (2005). Evolution of indirect reciprocity. Nature, 437 (27), 1291-1298.

Sober, E. \& Wilson, D. S. (1998). Unto Others. The Evolution and Psychology of Unselfish Behavior. Cambridge, MA: Harvard University Press.

Tannen, D. (1984). Conversational style - Analyzing talk among friends. Norwood: Ablex Publishing Corporation.

Tomasello, M. (2006). Why don't apes point?. In N. J. Enfield \& S. C. Levinson (Eds.), Roots of human sociality: Culture, cognition and interaction, 506524. Oxford: Berg Publishers.

Woodburn, J. (1982). Egalitarian societies. Man, 17, 431-451.

Zahavi, A. \& Zahavi, A. (1997). The handicap principle. New York: Oxford University Press. 